\title{
Diversity of $A B C$ transporter genes across the plant kingdom and their potential utility in biotechnology
}

Thomas S. Lane ${ }^{1,3}$, Caroline S. Rempe ${ }^{1,3}$, Jack Davitt ${ }^{2}$, Margaret E. Staton ${ }^{2}$, Yanhui Peng ${ }^{3}$, Douglas Edward Soltis ${ }^{4,5,6}$, Michael Melkonian ${ }^{7}$, Michael Deyholos ${ }^{8}$, James H. Leebens-Mack' ${ }^{9}$ Mark Chase ${ }^{10,11}$, Carl J. Rothfels ${ }^{12}$, Dennis Stevenson ${ }^{13}$, Sean W. Graham ${ }^{14}$, Jun Yu ${ }^{15}$, Tao Liu ${ }^{16}$, J. Chris Pires ${ }^{17}$, Patrick P. Edger ${ }^{18}$, Yong Zhang ${ }^{19}$, Yinlong Xie ${ }^{18,19,20}$, Ying Zhu ${ }^{18}$, Eric Carpenter ${ }^{21}$, Gane Ka-Shu Wong ${ }^{18,21,22}$ and C. Neal Stewart Jr. ${ }^{1,3^{*}}$

\begin{abstract}
Background: The ATP-binding cassette (ABC) transporter gene superfamily is ubiquitous among extant organisms and prominently represented in plants. $A B C$ transporters act to transport compounds across cellular membranes and are involved in a diverse range of biological processes. Thus, the applicability to biotechnology is vast, including cancer resistance in humans, drug resistance among vertebrates, and herbicide and other xenobiotic resistance in plants. In addition, plants appear to harbor the highest diversity of $A B C$ transporter genes compared with any other group of organisms. This study applied transcriptome analysis to survey the kingdom-wide ABC transporter diversity in plants and suggest biotechnology applications of this diversity.

Results: We utilized sequence similarity-based informatics techniques to infer the identity of $A B C$ transporter gene candidates from 1295 phylogenetically-diverse plant transcriptomes. A total of 97,149 putative (approximately $25 \%$ were full-length) ABC transporter gene members were identified; each RNA-Seq library (plant sample) had $88 \pm 30$ gene members. As expected, simpler organisms, such as algae, had fewer unique members than vascular land plants. Differences were also noted in the richness of certain $A B C$ transporter subfamilies. Land plants had more unique $A B C B$, $A B C C$, and $A B C G$ transporter gene members on average $(p<0.005)$, and green algae, red algae, and bryophytes had significantly more ABCF transporter gene members $(p<0.005)$. Ferns had significantly fewer ABCA transporter gene members than all other plant groups $(p<0.005)$.

Conclusions: We present a transcriptomic overview of $A B C$ transporter gene members across all major plant groups. An increase in the number of gene family members present in the $A B C B, A B C C$, and $A B C D$ transporter subfamilies may indicate an expansion of the $A B C$ transporter superfamily among green land plants, which include all crop species. The striking difference between the number of ABCA subfamily transporter gene members between ferns and other plant taxa is surprising and merits further investigation. Discussed is the potential exploitation of $A B C$ transporters in plant biotechnology, with an emphasis on crops.
\end{abstract}

Keywords: ABC transporter, Transcriptomics, Computational biology, Taxonomic diversity

\footnotetext{
*Correspondence: nealstewart@utk.edu

'The Graduate School of Genome Science and Technology, University of

Tennessee, Knoxville, TN 37996, USA

${ }^{3}$ Department of Plant Sciences, University of Tennessee, Knoxville, TN 37996,

USA

Full list of author information is available at the end of the article
}

(c) 2016 The Author(s). Open Access This article is distributed under the terms of the Creative Commons Attribution 4.0 International License (http://creativecommons.org/licenses/by/4.0/), which permits unrestricted use, distribution, and reproduction in any medium, provided you give appropriate credit to the original author(s) and the source, provide a link to the Creative Commons license, and indicate if changes were made. The Creative Commons Public Domain Dedication waiver (http://creativecommons.org/publicdomain/zero/1.0/) applies to the data made available in this article, unless otherwise stated. 


\section{Background}

The ATP-binding cassette $(\mathrm{ABC})$ transporter family is one of the largest known protein superfamilies in biology, which is represented in all living organisms [1-7]. Shared among members within the $\mathrm{ABC}$ transporter protein superfamily is the ability to hydrolyze adenosine triphosphate (ATP), which is used in a wide array of functions, including DNA repair, RNA translocation, and most commonly, active transport of a wide variety of substrates across various types of membranes in cells [3].

ABC transporters have three structural types. Full transporters are composed of two transmembrane domains (TMD) and two nucleotide-binding domains (NBD). Half transporters are composed of one TMD and one NBD, which dimerize in pairs to create virtual full transporters as homodimers or heterodimers. A third type of transporter has no TMDs but two NBDs [5]. The NBD is present in all three structural types and contains many key conserved motifs: Walker A, Q-loop, Walker B, D-loop, switch H-loop, and a signature motif (LSGGQ). The Dloop primarily functions in holding dimers together, the switch $\mathrm{H}$-loop interacts with the transmembrane domain, the Walker A and B motifs form the P-loop, which binds to ATP, and the Q-loop and H-loop contain residues important for interacting with the $\gamma$-phosphate of the ATP [3]. Finally, the signature motif (LSGGQ) is exclusively found in $A B C$ proteins, which enables $A B C$ proteins to be distinguished from other ATPases [7].

In plants, a full inventory of ABC transporters was first catalogued for Arabidopsis thaliana [8], partially characterized $[9,10]$. The current and most widely used classification system for $\mathrm{ABC}$ transporter subfamilies in plants is based on protein solubility, presence of TMDs, function, and amino acid sequence [5]. In our current study we used the system described in [5], which is consistent with the Human Genome Organization (HUGO) designation but including another subfamily, subfamily I. Plant $\mathrm{ABC}$ transporters fall into eight subfamilies using this nomenclature: A, B, C, D, E, F, G, and I (Table 1). $\mathrm{ABCH}$ subfamily members, a ninth subfamily, have not been identified in plants. Soluble proteins lacking TMDs such as the $\mathrm{ABCF}$ and $\mathrm{ABCE}$ members of the $\mathrm{ABC}$ transporter protein superfamily, despite being called such, lack any transport phenomena [5]. Despite the obvious importance of $\mathrm{ABC}$ transporters in plants, relative to other organisms there is a dearth of functional studies on individual members in plant as well as -omics studies; typically studies are limited to a few dicot species [8-14].

There are several known functions of ABC transporters of agricultural importance. One of the most important is detoxification. Detoxification mechanisms are of particular interest in herbicide resistance studies, particularly those involving putative glyphosate sequestration into vacuoles [15-17]. The Arabidopsis pleiotropic drug resistance 9 (PDR9) is also known to confer auxinic herbicide resistance [18]. Export proteins are also involved in environmental response and plant development such as auxin exporters ABCB19 and ABCB1 [19]. Importers primarily function in the acquisition of substrates important for cellular activity and ultimately the plant's survival. Such is the case of AtPMP2, which imports critical substrates needed in the glyoxylate cycle during germination [20].

The main objective of our study was to survey the diversity of $\mathrm{ABC}$ transporters across plants using a new public resource for plant transcriptomes, the One Thousand Plants Transcriptome Project (1KP). 1KP includes raw transcript data as well as assembled reference transcriptomes generated with standardized processing procedures. These data included transcriptomes from two species with extant reference genomes: Ricinus communis (castor bean) and Linum usitatissmum (flax), which acted as internal controls for matching the $1 \mathrm{KP}$ transcriptomes with the published reference genomes. These resources offer a source of transcriptome sequencing data spanning the breadth of diversity of plants [13, 21-24].

\section{Methods}

\section{Data acquisition and quality control}

All of the data in this project, including raw sequence reads, transcriptome assemblies, and assembly statistics, were gathered from the $1 \mathrm{KP}$ collaborative project [21]. The 1KP consortium performed all sample collection, sequencing, quality control, and assembly [13, 21]. A total of 1462 assemblies, assembled with SOAP de novo, were downloaded from the $1 \mathrm{KP}$ repository $[11,25]$. Because some crucial taxonomic information was missing from accompanying data files, 161 samples were excluded from subsequent analysis. Another six samples were removed because of contamination that was discovered during the quality control step. The remaining 1295 1KP samples were translated into six frames using the Transeq program from EMBOSS (The European Molecular Biology Open Software Suite) [26]. A sixframe translation coupled with searches amongst confirmed $\mathrm{ABC}$ transporter protein sequences enabled us to assign each transcript into the correct reading frame for analysis. Since well-annotated genomes exist for only a handful of species analyzed and most species lacked sufficiently large and diverse tissue sequencing results, alternative splice variants were not considered.

\section{HMMER domain e-value selection}

The full sets of Arabidopsis and rice protein sequences were obtained from Phytozome version 10, including the Arabidopsis ABC transporter protein list [5] and rice list 
Table 1 A comparison of different nomenclature systems for $A B C$ proteins

\begin{tabular}{|c|c|c|c|c|c|c|}
\hline $\begin{array}{l}\text { HUGO } \\
\text { subfamily }\end{array}$ & Sánchez-Fernández subfamily ${ }^{a}$ & ABCISSE family & ABCISSE subfamily & TC subfamily ${ }^{d}$ & $\begin{array}{l}\text { Domain } \\
\text { organization }\end{array}$ & Taxa \\
\hline \multirow[t]{2}{*}{$A B C A$} & ABC1 homologue $(\mathrm{AOH})$ & \multirow[t]{2}{*}{ Drug and antibiotic resistance (DRA) } & \multirow[t]{2}{*}{$\mathrm{ABCA}$} & \multirow{2}{*}{$\begin{array}{l}\text { Cholesterol/phospholipid/ } \\
\text { retinal flippase (CPR) }\end{array}$} & (TMD-NBD)2 & eukaryotes (not yeast) \\
\hline & ABC2 homologue (ATH) & & & & TMD-NBD & eukaryotes \\
\hline \multirow[t]{4}{*}{$A B C B$} & Multidrug resistance (MDR) & \multirow{4}{*}{$\begin{array}{l}\text { Drug, peptides and lipid export } \\
\text { (DPL) }\end{array}$} & p-glycoprotein (p-GP) & MDR & (TMD-NBD)2 & prokaryotes and eukaryotes \\
\hline & $\begin{array}{l}\text { Transporter associated with } \\
\text { antigen processing (TAP) }\end{array}$ & & $\begin{array}{l}\text { TAP and multidrug } \\
\text { resistance-like protein (MDL) }\end{array}$ & $\begin{array}{l}\text { TAP and mitochondrial } \\
\text { peptide exporter (MPE) }\end{array}$ & TMD-NBD & eukaryotes \\
\hline & $\begin{array}{l}\text { ABC transporter of the } \\
\text { mitochondria (ATM) }\end{array}$ & & Heavy metal tolerance (HMT) & HMT & TMD-NBD & eukaryotes \\
\hline & - & & $\begin{array}{l}\text { Lipid A-like exporter, putative } \\
\text { (LLP) }\end{array}$ & - & TMD-NBD & prokaryotes and plants \\
\hline$A B C C$ & $\begin{array}{l}\text { Multidrug resistance associated } \\
\text { protein (MRP) }\end{array}$ & $\begin{array}{l}\text { Organic anion conjugates and drug } \\
\text { export (OAD) }\end{array}$ & MRP & Conjugate transporter $(\mathrm{CT})$ & (TMD-NBD)2 & eukaryotes \\
\hline$A B C D$ & $\begin{array}{l}\text { Peroxisomal membrane protein } \\
\text { (PMP) }\end{array}$ & Fatty acid export (FAE) & - & $\begin{array}{l}\text { Peroxisomal fatty acyl-CoA } \\
\text { transporter (P-FAT) }\end{array}$ & $\begin{array}{l}\text { TMD-NBD; } \\
\text { (TMD-NBD)2 }\end{array}$ & bacteria and eukaryotes \\
\hline$A B C E$ & RNase L inhibitor (RLI) & RNase L inhibitor (RLI) & - & - & NBD-NBD & archaea and eukaryotes \\
\hline $\mathrm{ABCF}$ & $\begin{array}{l}\text { General control non-repressible } \\
\text { (GCN) }\end{array}$ & $\begin{array}{l}\text { Antibiotic resistance and translation } \\
\text { regulation (ART) }\end{array}$ & $\begin{array}{l}\text { Gene expression regulation } \\
\text { (REG) }\end{array}$ & - & NBD-NBD & bacteria and eukaryotes \\
\hline \multirow[t]{2}{*}{$A B C G$} & $\begin{array}{l}\text { White-brown complex } \\
\text { homologue (WBC) }\end{array}$ & $\begin{array}{l}\text { Eye pigment precursors and drugs } \\
\text { (EPD) }\end{array}$ & WHITE & $\begin{array}{l}\text { Eye pigment precursor } \\
\text { transporter (EPP) }\end{array}$ & NBD-TMD & bacteria and eukaryotes \\
\hline & Pleiotropic drug resistance (PDR) & & PDR & PDR & (NBD-TMD)2 & plants and fungi \\
\hline $\mathrm{ABCH}$ & - & $\begin{array}{l}\text { Drug resistance, bacteriocin and } \\
\text { lantibiotic immunity (DRI) }\end{array}$ & $\mathrm{YHIH}$ & & NBD-TMD & $\begin{array}{l}\text { prokaryotes, slime moulds, } \\
\text { echinoderms, insects and fish }\end{array}$ \\
\hline
\end{tabular}

References: ${ }^{a}[8]$, b $[6],{ }^{c}[4],{ }^{d}[52]$, Figure reprinted from [5] with permission 
[27] Additional file 1. The hmmscan program from the HMMER package version 3.1 was used to search for the pfam record PF00005 across the full Arabidopsis and rice protein data sets $[5,28,29]$. A pfam record, such as the PF00005 domain, is a hidden Markov model based on a multiple sequence alignment of protein domains; in the case of PF00005 this multiple sequence alignment is of the NBD of many different ABC transporter proteins. A cutoff e-value of 3.10E-18 was selected in the two data sets that maximizes true positives (reported actual ABC transporters) and minimizes false negatives (reported as non-ABC transporters).

\section{Comparison of genome and transcriptome data sources}

The full set of flax and castor bean proteins were obtained from Phytozome v10 [30, 31]. Three sets of transcriptomic data for flax (shoot sample 1, shoot sample 2, shoot sample 3) and one set of castor bean (mixed tissue sample) were obtained from the $1 \mathrm{KP}$ data set $[11,25]$. The hmmscan program was used to search for PF00005 pfam domains among all six sets of data using an evalue of $3.10 \mathrm{E}-18$, yielding six sets of putative $A B C$ transporter genes.

\section{$A B C$ transporter classification}

Each sample's translated transcriptome was searched using hmmscan [28]. Search results containing the PF00005 pfam domain with an e-value of $3.10 \mathrm{E}-18$ were subjected to further classification using best BLAST searches [32]. The de novo assembled transcriptomes from the $1 \mathrm{KP}$ data set were fragmented, transporters containing multiple nucleotide binding domains may only have had one of their binding domains accounted for in the transcriptomes sequencing results. Determination of $\mathrm{ABC}$ transport protein family was made strictly using BLAST searches against known $A B C$ transport proteins in Arabidopsis and rice. A specialized database of known plant $\mathrm{ABC}$ transporters from Arabidopsis and rice was constructed for subfamily classification purposes using legacy BLAST formatdb version 2.2.26 (Additional file 2: Table S1). All known plant $A B C$ transporter subfamilies were represented in our BLAST database.
Each of the $12951 \mathrm{KP}$ subsamples along with flax and castor bean genome-derived proteomes were used to query the $\mathrm{ABC}$ transporter database using legacy BLAST version 2.2.26, in each case the best hit to the $A B C$ transporter database was used to classify the query among one of the eight $\mathrm{ABC}$ transporter subfamilies.

\section{Nonparametric comparison of $A B C$ diversity}

JMP version 11 [33] was used to perform a one-way analysis of counts by species and performed pairwise nonparametric comparisons using the Wilcoxon method. All subfamily and total $A B C$ transporter gene member classifications were subjected to pairwise analysis between each of the groups: angiosperms, conifers, ferns, lycophytes, mosses, hornworts, liverworts, chlorophytes, charophytes, glaucophytes, rhodophytes, and Chromista.

\section{Results and discussion $A B C$ protein discovery}

The pfam record PF00005 represents the highly conserved ATP-binding domain of $A B C$ transporters. We used this pfam record to identify $A B C$ transporter gene members across an entire transcriptome database as well as full gene sets of Arabidopsis and rice (Table 2). ABC transporter protein sequences had much lower expectation values for the PF00005 pfam domain from the hmmscan than did known non-ABC transporter protein sequences $(85 \%$ of the top 200 lowest e-value hits were known $\mathrm{ABC}$ transporter proteins) (Additional file 3: Table S2). These results were obtained using 233 known $\mathrm{ABC}$ transporters and 85,152 known non-ABC transporter protein sequences. While the pfam search was effective in $A B C$ transporter gene member discovery, there was not a clear delineation in e-value scores between known gene family members and other genes. The highest e-value among known $\mathrm{ABC}$ transporters was 2.10E-10. However, some non- $\mathrm{ABC}$ transporters showed e-values lower than the 2.10E-10 cutoff. Searching among the top five highest e-values we identified the largest gap between e-values of 3.10E-18 and 2.10E-15. This gap represents three orders of magnitude between non- $\mathrm{ABC}$ transporters and $\mathrm{ABC}$ transporters. Using the 3.10E-18 threshold of significance, we identified 282

Table 2 A summary of HMMER search results

\begin{tabular}{lllllcc}
\hline E-value cutoff & True positives & False positives & True negatives & False negatives & Specificity & Sensitivity \\
\hline $3.10 \mathrm{E}-21$ & 222 & 48 & 84,882 & 11 & 0.9994 & 0.9528 \\
$3.10 \mathrm{E}-18$ & 230 & 52 & 84,870 & 3 & 0.9994 & 0.9871 \\
$2.10 \mathrm{E}-15$ & 231 & 52 & 84,869 & 2 & 0.9994 & 0.9914 \\
$2.10 \mathrm{E}-13$ & 232 & 55 & 84,865 & 1 & 0.9994 & 0.9957 \\
$2.10 \mathrm{E}-10$ & 233 & 64 & 84,855 & 0 & 0.9992 & 1.0000 \\
\hline
\end{tabular}

Summary of sensitivity and specificity of 85,152 HMMER queries against pfam as a method for selecting an appropriate cutoff e-value for the identification of PF00005 (ABC transporter) domains 
sequences as $\mathrm{ABC}$ transporters. Of the 282 sequences identified as $A B C$ transporters, 230 had been previously classified as $A B C$ transporters, but 52 were not (putative false positives). Therefore, the cutoff excluded three known $\mathrm{ABC}$ transporters (putative false negatives). With the entire set of 85,152 starting sequences, the usage of the pfam PF00005 domain yielded a sensitivity (true positives divided by true positive plus false negatives) of 0.9871 and a specificity of 0.9994 (true negatives divided by true negatives plus false positives). Consequently, an e-value of 3.10E-18 was selected as the optimum, which allowed a total of three false negatives for $A B C$ transporter detection for all further HMMER analysis.

\section{Comparison of genome and transcriptome data sources}

The flax and castor bean transcriptomes allowed us to examine how the number of expressed $A B C$ transporters identified in $1 \mathrm{KP}$ corresponds to the number of known $\mathrm{ABC}$ transporters in their entire genomes, which allowed us to make inferences throughout the plant kingdom, with caveats. $\mathrm{ABC}$ transporter genes are known to have variable expression across tissues [11], and thus their identification from RNA-Seq data is unlikely to yield a complete complement of gene family members for an organism.

The 1KP-generated assemblies for flax had 99,855, 95,813 , and 101,110 total putative transcripts for each library. The number of transcripts identified by hmmscan as $A B C$ protein transporter gene members was similar between the three flax samples: 82, 91, and 92. These figures represented $42-47 \%$ of the number of $\mathrm{ABC}$ transporters identified from the reference genome protein sequences. A total of 59 transcripts were putatively identified as $\mathrm{ABC}$ transporters from the single available castor bean transcriptome from $1 \mathrm{KP}, 42 \%$ of the 142 putative genes identified in the genome-sequence derived gene set.

Subfamilies for putative $\mathrm{ABC}$ transporters were assigned on the basis of the most similar amino acid sequence from Arabidopsis or rice. The distribution of the $\mathrm{ABC}$ transporters among the eight subfamilies shared a similar pattern between the $1 \mathrm{KP}$ transcriptome samples and the reference genome-derived gene sets (Figs. 1a and $\mathrm{b}$ ).

In general, the $1 \mathrm{KP}$ data per accession contained nearly half the number of unique $\mathrm{ABC}$ transporter gene members, by comparison, to their reference genome counterparts as identified by hmmscan searches. In addition, hmmscan found nearly the same number of unique $A B C$ transporters for each of the three $1 \mathrm{KP}$ data sets for flax. The relative consistency between corresponding $1 \mathrm{KP}$ data samples is encouraging for extension of inferences across data sets in order to estimate the total number of gene family members for all plant taxa.

\section{ABC transporter subfamily classification}

The majority of our knowledge about the $\mathrm{ABC}$ transporter protein superfamily in plants is from studies limited to a few angiosperm species. In an effort to expand our knowledge of the varying representation of $A B C$ transporter protein subfamilies across the plant kingdom, we classified nearly 97,149 transcripts across 1295 samples into one of the seven $\mathrm{ABC}$ transporter HUGO subfamilies (A, B, C, D, E, F, G) and the plant-only subfamily, I [5]. The $12951 \mathrm{KP}$ samples span a diversity of plant taxa: 816 from angiosperms, 76 from conifers, 71 ferns, 22 lycophytes, 25 liverworts, 41 mosses, 6 hornworts, 123 chlorophytes, 46 charophytes, 5 glaucophytes, and 28 rhodophytes. In general, the results comparing hornworts/glaucophytes and other plants were not significant, likely owing to the small sample sizes in these
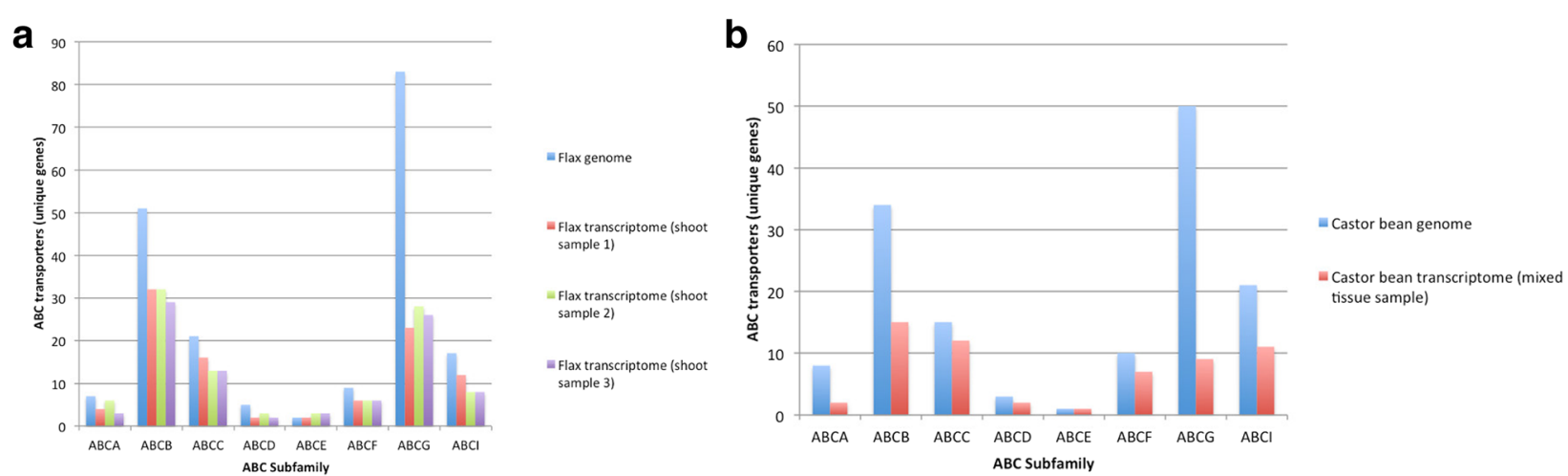

Fig. 1 Flax and castor bean $A B C$ transporter unique gene distribution inferred from RNA-Seq transcriptome data. a Plot comparing total $A B C$ transporter unique genes observed in the flax genome and the three 1KP transcriptomes for flax (shoot sample 1, shoot sample 2, shoot sample 3). b Plot comparing total $\mathrm{ABC}$ transporter unique genes observed in the castor bean genome and the 1KP transcriptomes for castor bean (mixed tissue sample). Searches based on hmmscan searches for the PF00005 pfam domain and subsequent BLAST queries against a custom BLAST database of ABC transporters from Arabidopsis and rice 
groups. The breadth of samples across various plant groups provides robust statistical support for comparisons amongst groups in most cases. The gymnosperms were mainly represented by conifers, with few other gymnosperms being represented: three Gnetales, four Cycadales, and one Ginkgoales.
The hmmscan analysis with a cutoff of 3.10E-18 found at least 50 unique $\mathrm{ABC}$ genes (transcripts) containing PF00005 pfam domains per plant sample (Fig. 2a). In many cases, we recorded outliers, the largest of which, Blasia sp. (526 ABC transporters), more than doubled the next largest sample. For ease of interpretation, the

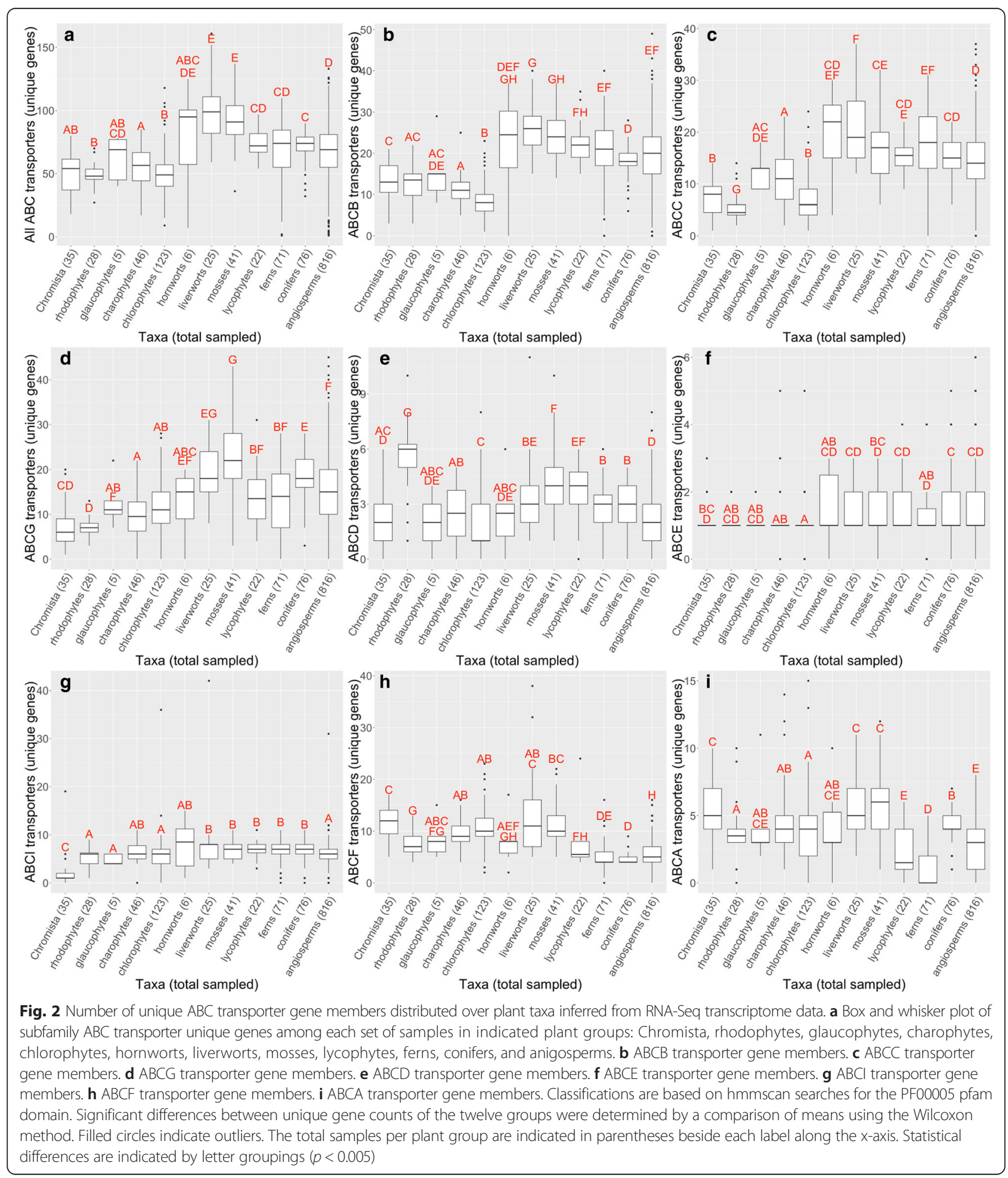


Blasia sp. sample was omitted from figures in most cases. Bryophytes, lycophytes, conifers, ferns, and angiosperms had 16 to 43 more $\mathrm{ABC}$ transporter transcripts than rhodophytes, chlorophytes, charophytes, glaucophytes, and Chromista. Many observed differences in average number of transporters between plant groups were found to be significant $(p<0.005)$. Although green algae and land plants have been shown to harbor similar numbers of $\mathrm{ABC}$ transporter subfamily gene members and total $\mathrm{ABC}$ transporter genes [34], the simpler transport systems of green algae, rhodophytes, glaucophytes, and Chromista may contribute to the reduced number of unique $\mathrm{ABC}$ transporter genes we observed on our study. Angiosperms, conifers, ferns, chlorophytes, charophytes, glaucophytes, rhodophytes, and Chromista had 22 to 43 fewer unique $\mathrm{ABC}$ transporter gene members than bryophytes. The differences in mean number of transporters between these groups is also significant, with exception to hornworts $(p<0.005)$.

Results from BLAST subfamily classifications were used to identify full-length transcripts based on query coverage. Because the $\mathrm{ABC}$ transport protein subfamilies split prior to the most recent common ancestor of all plants, it is likely that $\mathrm{ABC}$ transport protein subfamily members will closely match an ortholog of the same subfamily. Transcripts with greater than $90 \%$ of the query aligned to the target sequence were classified as full length. All 1295 transcriptome samples contained at least one putative unique $\mathrm{ABC}$ transporter gene member with 97,149 ABC transporters identified across all samples. A total of 22,343 ABC transporter sequences were identified as full length. There were, on average, $66 \mathrm{ABC}$ transporter gene members discovered per RNA-Seq library with a standard deviation of 26 gene members (Fig. 2a). Most samples (1052 of 1295) contained at least one of each of the ABC transporter protein subfamily members.

The number of unique $\mathrm{ABC}$ transporter subfamily gene members varied between distantly related plants. Among the functionally diverse subfamilies $\mathrm{ABCB}$ and $\mathrm{ABCC}$, we saw significantly fewer unique $\mathrm{ABC}$ transporter gene members on average in algae ( 5 to 15 gene members) than in other groups: angiosperms, conifers, ferns, lycophytes, and bryophytes $(p<0.005)$ (Figs. $2 \mathrm{~b}$ and c). Among ABCG subfamily transporters the differences in the average number of $A B C$ transporter gene members seen between algae was significantly lower ( 5 to 11 gene members) than the following groups: angiosperms, conifers, and bryophytes $(p<0.005)$ (Fig. 2d).

Several studies have indicated that plant genomes have more $\mathrm{ABCB}, \mathrm{ABCC}$ and/or ABCG subfamily gene members in comparison to other eukaryotes such as human and yeast [5, 35]. Our results revealed additional variability among plants regarding the size of these subfamilies, specifically in that algae contain relatively fewer unique $\mathrm{ABCB}, \mathrm{ABCC}$ and $\mathrm{ABCG}$ transporter members. The larger number of unique $\mathrm{ABCB}$ transporter gene members seen in vascular plant species may have adaptive significance for complex and heterogeneous environments of "higher plants." Land plants' best defense against xenobiotics, such as heavy metals, might come from $\mathrm{ABCB}$ transporters' ability to sequester and/or transport foreign chemicals. For example, AtABCB25, an Arabidopsis ABCB export protein, allows some tolerance to cadmium and lead when overexpressed [36, 37]. The overexpression data are useful to infer functional significance, but also guide potential utility in biotechnology. Aluminum tolerance is conferred by the expression of $\mathrm{ABCB} 27$ in root tips [38]. ABCC transporter proteins have been identified among plants for their role in detoxification and the regulation of stomatal guard cells [39]. The gap in types of $\mathrm{ABCC}$ transporter transcript number seen between algae and other plant taxa might be explained by a lack of need by algae for stomata regulation and/or detoxification. While liverworts also lack stomata we do not see significantly fewer $\mathrm{ABCC}$ transporter proteins among liverworts. Algae do not require the specialized transport systems of land plants because most cells have direct access to nutrients in their water environment. Such direct access to an aquatic environment may contribute to fewer unique gene members of subfamilies $\mathrm{ABCB}$ and $\mathrm{ABCC}$. Only $26 \mathrm{ABC}$ transport proteins were found in Ceratophyllum demersum, relative to average $66 \mathrm{ABC}$ transport proteins seen across all 1295 tissues sampled. This finding would appear to support the reduced expression of $A B C$ transport proteins in an aquatic environment (Additional file 4: Table S3). Algae also do not produce a waxy cuticle - so reduced ABCG transcripts may be related to a lack of the ABCG transporter proteins that are necessary for the transport of cuticular lipids [40, 41]. Whether the variation in size of these families is a result of gene expansion is unclear and requires further investigation for evaluation.

Among subfamilies $\mathrm{ABCD}, \mathrm{ABCE}$, and $\mathrm{ABCI}$, few significant differences were observed in the average number of gene members across plants with a single exception in the ABCD subfamily (Figs. 2e, f, and g). Significant differences in the average number of $\mathrm{ABC}$ transporter gene members detected among $\mathrm{ABCD}, \mathrm{ABCE}$, and $\mathrm{ABCI}$ were small, ranging from zero to two $(p<0.005)$. The presence of $\mathrm{ABCD}, \mathrm{ABCE}$, and $\mathrm{ABCI}$ transcripts with very similar gene member averages might suggest that the proteins that result from the translation of these transcripts are essential to life among all plants. Plant ABCD transporters are well known for their import of substrates necessary in the glyoxylate cycle [20]. It seems likely that plants retaining $\mathrm{ABCD}$ transporters would 
have an evolutionary advantage over plants that do not, given the importance of the glyoxylate cycle to survival across all plant taxa. Rhodophytes have nearly double, on average, the number of ABCD subfamily members compared with other plants. We can speculate that since these $A B C D$ transporters are peroxisome-localized and important for fatty acid metabolism, especially long chain fatty acids, and that Rhodophyta produce a high number of long-chain fatty acids [42], that there may be functional significance. Rhodophytes might be good targets to mine $\mathrm{ABCD}$ transporters for use to produce novel oils in crops. ABCE proteins are found in archaea, bacteria, and eukaryotes, suggesting that this class of $\mathrm{ABC}$ transporter proteins is essential to life and are thus conserved [5]. ABCE1 is a translation termination factor [43]. Once a ribosome reaches a stop codon, ABCE1 helps to detach the ribosome from the mRNA [44], and also plays an important role in ribosome recycling [45]. The maintenance of similar numbers of unique ABCD and $A B C E$ subfamily gene members may be because of the conservation of essential functions provided by those subfamilies. Our understanding of the ABCI subfamily, is expected to be significantly improved as more information regarding the structure and function of the subfamily members becomes available. However, current data suggest the origins of ABCI subfamily transporter genes may be from prokaryotic genomes and so they may result from a movement of genes from mitochondria and plastids to the nuclear genome. As such, the $\mathrm{ABCI}$ transporter proteins have been classified as a heterogeneous group composed of multicomponent transporters (reviewed in [5]) so the similarity seen in average number of unique gene members across plant taxa was unexpected.

In the case of ABCF subfamily proteins, we observed significantly higher transcript count averages in Chromista, glaucophytes, rhodophytes, chlorophytes, charophytes, and bryophytes than in all other groups, four to seven more transcripts on average than angiosperms, conifers, ferns, and lycophytes $(p<0.005)$ (Fig. 2h). When directly comparing algae and bryophytes, we found that bryophytes had more unique ABCF subfamily gene members on average $(p<0.005)$. Understanding the increased variation, specifically regarding the ABCF subfamily size among algae and bryophytes is difficult with a lack of functional characterization of ABCF proteins among plants. Studies in yeast and humans have indicated ABCF protein function in the activation of eIF- $2 \alpha$ kinase [5]. Activation of eIF-2 $\alpha$ kinase is important in the regulation of stress response factors [46]. Indeed one member of the ABCF, ABC50 appears to play an especiallyimportant role in mammalian translation processes in interactions with eiF2 and the ribosome $[47,48]$. There is a published patent application in which ABC50 is claimed to be useful to increase protein in plants, among other organisms [49]. We noted an increase in the total number of ABCF protein gene members among algae and bryophytes; we cannot speculate about the potential adaptive significance.

The average number of unique ABCA subfamily transporter gene members was significantly lower in ferns, three to four less gene members on average in most cases $(p<0.005)$ (Fig. 2i). There was a significant difference between the average number of unique ABCA transporter gene members in ferns, conifers, and angiosperms $(p<0.005)$. While little is known about the function of ABCA transporter proteins among plants, they are suspected to be involved in lipid metabolism based on their known function in humans (reviewed in [50]). Upon comparison with Arabidopsis, rice was found to be missing an orthologous full length ABCA transporter, which is consistent with previously published results [51]. Our results indicate an occurrence of decreased ABCA transporter genes among ferns relative to other plant groups, possibly from gene loss. While the single gene loss observed in rice and the results observed in fern are likely unrelated, they may point to similar phenomena regarding the importance of $\mathrm{ABCA}$ transport proteins in sterol metabolism [52].

\section{Conclusions}

$\mathrm{ABC}$ transport proteins have diverse functions and are ubiquitous in plants. We catalogued $\mathrm{ABC}$ transporters across the plant kingdom from hundreds of transcriptomes. While our current study was constrained by imperfect transcriptome assemblies taxonomic patterns should be of interest to the community to build hypotheses. Specifically, we found significant differences in the number of unique $A B C$ transporter gene members between algae (Chromista, rhodophytes, glaucophytes, chlorophytes, and charophytes), bryophytes (mosses, liverworts, hornworts), lycophytes, ferns, conifers (other gymnosperms were not well represented among the $1 \mathrm{KP}$ data), and angiosperms. Algae and bryophytes have fewer unique $\mathrm{ABC}$ transporter gene members than lycophytes, ferns, conifers, and angiosperms. The number of unique $\mathrm{ABCD}, \mathrm{ABCE}$, and $\mathrm{ABCI}$ subfamily protein gene members show few significant differences amongst plants. With regards to plant biotechnology applications, it is noted that these three subfamilies might not provide much novelty. In contrast, the diversity of $\mathrm{ABCB}$ and $\mathrm{ABCF}$ proteins, known for detoxification and stress resistance, respectively, are attractive genes to screen for improving crops via biotechnology. Especially intriguing are the $\mathrm{ABCF}$ members in algae and bryophytes for potential use in crop biotechnology. Given the diversity and function of ABCF members, algae and bryophytes have been largely ignored as sources of potentially useful genes in agriculture. 


\section{Additional files}

Additional file 1: file S1. Fasta file of $A B C$ transporter proteins from rice and Arabidopsis. (FASTA $139 \mathrm{~kb}$ )

Additional file 2: Table S1. Detailed table of HMMER testing results. (XLSX $82 \mathrm{~kb}$ )

Additional file 3: Table S2. Detailed table of classification results and associated metadata. (XLSX $163 \mathrm{~kb}$ )

Additional file 4: Table S3. Filtered BLAST results of transcripts with $90 \%$ or greater query coverage of $A B C$ transporter protein subject. (XLSX 2317 kb)

\section{Acknowledgments}

The authors would like to thank Dylan Storey for his suggestions and advice regarding the handling, storage, and analysis of the $1 \mathrm{KP}$ data.

\section{Funding}

The authors thank the University of Tennessee Genome Science and Technology graduate program for providing funds to TL, whose project was also supported by UT AgResearch and the Racheff endowment. We also thank the financial supporters of the 1KP consortium.

\section{Availability of data and materia}

All sequence data used in this paper are made available in the supplements. See 1KP.org for updates on all data on the larger 1KP project.

\section{Authors' contributions}

TSL designed and performed the data analyses and drafted the manuscript. CSR co-conceived the strategy for separating putative $A B C$ transporter transcripts into respective $A B C$ transporter subfamilies and was involved in the collection of known $A B C$ transporter proteins. JD performed statistical analysis based on data. YP provided insights regarding the form and function of $A B C$ transporters among plant species and provided the initial list of known plant $A B C$ transporters. MES contributed strategies for verifying analyses performed. DES, MM, MD, JHL-M, MC, CJR, DS, SWG, JY, TL, JCP, PPE, YZ, YX, YZ, EC, GK-SW, and CNS are members of the $1 \mathrm{KP}$ consortium and were involved in $1 \mathrm{KP}$ organization and structure, sample collection and sequencing. CNS was partially responsible for the conception of the study and writing. All authors agree with the contents of the manuscript.

\section{Competing interests}

The authors declare that they have no competing interests.

\section{Ethics approval and consent to participate}

No animals or humans were used in the research.

\section{Author details}

${ }^{1}$ The Graduate School of Genome Science and Technology, University of Tennessee, Knoxville, TN 37996, USA. ²Department of Entomology and Plant Pathology, University of Tennessee, Knoxville, TN 37996, USA. ${ }^{3}$ Department of Plant Sciences, University of Tennessee, Knoxville, TN 37996, USA.

${ }^{4}$ Department of Biology, University of Florida, Gainesville, FL 32611, USA. ${ }^{5}$ Florida Museum of Natural History, Gainesville, FL 32611, USA. ${ }^{6}$ Genetics Institute, University of Florida, Gainesville, FL 32611, USA. ${ }^{7}$ Department of Biology, Cologne Biocenter, University of Cologne, Cologne 50674, Germany. ${ }^{8}$ Department of Biology, University of British Columbia, Kelowna, BC V1V 1V7, Canada. ${ }^{9}$ Department of Biological Sciences, University of Georgia, Athens, GA 30602, USA. ${ }^{10}$ Jodrell Laboratory, Royal Botanic Gardens Kew, Richmond, Surrey TW9 3AE, UK. ${ }^{11}$ Department of Biology, Duke University, Durham, NC 27708, USA. ${ }^{12}$ Department of Integrative Biology, University of California, University Herbarium, Berkeley, CA 94720-2465, USA. ${ }^{13}$ New York Botanical Garden, Bronx, New York, NY 10458, USA. ${ }^{14}$ Department of Botany, University of British Columbia, Vancouver, BC, Canada. ${ }^{15}$ CAS Key Laboratory of Genome Sciences and Information, Beijing Key Laboratory of Genome and Precision Medicine Technologies, Beijing Institute of Genomics, Chinese Academy of Sciences, Beijing 100101, People's Republic of China. ${ }^{16} \mathrm{College}$ of Marine Life Sciences, Ocean University of China, Qingdao 266003, People's Republic of China. ${ }^{17}$ Bond Life Sciences Center, Division of Biological Sciences, University of Missouri, Columbia, MO, USA. ${ }^{18}$ BGI-Shenzhen, Beishan
Industrial Zone, Yantian District, Shenzhen 518083, China. ${ }^{19}$ Department of Computer Science, HKU-BGl Bioinformatics Algorithms and Core Technology Research Laboratory, University of Hong Kong, Pokfulam, Hong Kong. ${ }^{20}$ School of Bioscience and Bioengineering, South China University of Technology, Guangzhou, China. ${ }^{21}$ Department of Biological Sciences, University of Alberta, Edmonton, AB T6G 2E9, Canada. ${ }^{22}$ Department of Medicine, University of Alberta, Edmonton, AB T6G 2E1, Canada.

Received: 1 March 2016 Accepted: 23 May 2016

Published online: 31 May 2016

\section{References}

1. Higgins CF. ABC transporters: from microorganisms to man. Annu Rev Cell Biol. 1992;8:67-113.

2. Jones PM, George AM. The $A B C$ transporter structure and mechanism: perspectives on recent research. Cell Mol Life Sci. 2004;61:682-99.

3. Davidson AL, Dassa E, Orelle C, Chen J. Structure, function, and evolution of bacterial ATP-binding cassette systems. Microbiol Mol Biol Rev. 2008;72:317-64.

4. Bouige P, Laurent D, Piloyan L, Dassa E. Phylogenetic and functional classification of ATP-binding cassette (ABC) systems. Curr Protein Pept Sci. 2002;3:541-59.

5. Verrier PJ, Bird D, Burla B, Dassa E, Forestier C, Geisler M, Klein M, Kolukisaoglu $U$, Lee $Y$, Martinoia E et al. Plant ABC proteins - a unified nomenclature and updated inventory. Trends Plant Sci. 2008;13:151-9.

6. Dassa $E$, Bouige $P$. The $A B C$ of $A B C$ : a phylogenetic and functional classification of $A B C$ systems in living organisms. Res Microbiol. 2001:152:211-29.

7. Davies TGE, Coleman JOD. The Arabidopsis thaliana ATP-binding cassette proteins: an emerging superfamily. Plant Cell Env. 2000;23:431-43.

8. Sanchez-Fernandez R, Davies TG, Coleman JO, Rea PA. The Arabidopsis thaliana ABC protein superfamily, a complete inventory. J Biol Chem. 2001; 276:30231-44

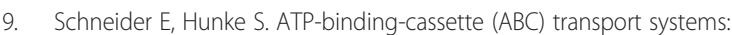
functional and structural aspects of the ATP-hydrolyzing subunits/domains. FEMS Microbiol Rev. 1998;22:1-20.

10. van den Brule S, Smart CC. The plant PDR family of ABC transporters. Planta. 2002;216:95-106.

11. Nguyen VN, Moon S, Jung KH. Genome-wide expression analysis of rice ABC transporter family across spatio-temporal samples and in response to abiotic stresses. J Plant Physiol. 2014;171:1276-88.

12. Cakir B, Kilickaya O. Whole-genome survey of the putative ATP-binding cassette transporter family genes in Vitis vinifera. PLoS One. 2013;8(11):e78860.

13. Matasci N, Hung L-H, Yan Z, Carpenter EJ, Wickett NJ, Mirarab S, Nguyen N, Warnow T, Ayyampalayam S, Barker M et al. Data access for the 1,000 Plants (1KP) project. Gigascience. 2014;3:17.

14. Adolfo G, Ruocco M, Di Donato A, Frusciante L, Lorito M, Scala F, Ercolano MR. Genetic variability and evolutionary diversification of membrane ABC transporters in plants. BMC Plant Biol. 2015;15:51.

15. Peng Y, Abercrombie LL, Yuan JS, Riggins CW, Sammons RD, Tranel PJ, Stewart Jr CN. Characterization of the horseweed (Conyza canadensis) transcriptome using GS-FLX 454 pyrosequencing and its application for expression analysis of candidate non-target herbicide resistance genes. Pest Manag Sci. 2010;66:1053-62.

16. Ge X, d'Avignon DA, Ackerman JJ, Sammons RD. Rapid vacuolar sequestration: the horseweed glyphosate resistance mechanism. Pest Manag Sci. 2010;66:345-8.

17. Hanson BD, Shrestha A, Shaner DL. Distribution of glyphosate-resistant horseweed (Conyza canadensis) and relationship to cropping systems in the Central Valley of California. Weed Sci. 2009;57:48-53.

18. Ito $\mathrm{H}$, Gray WM. A gain-of-function mutation in the Arabidopsis pleiotropic drug resistance transporter PDR9 confers resistance to auxinic herbicides. Plant Physiol. 2006;142:63-74.

19. Yang $H$, Murphy AS. Functional expression and characterization of Arabidopsis $\mathrm{ABCB}, \mathrm{AUX} 1$ and PIN auxin transporters in Schizosaccharomyces pombe. Plant J. 2009:59:179-91.

20. Theodoulou FL, Holdsworth M, Baker A. Peroxisomal ABC transporters. FEBS Lett. 2006:580:1139-55.

21. The One Thousand Transcriptomes Project [https://sites.google.com/a/ ualberta.ca/onekp/]. Accessed 28 May 2016.

22. Chan AP, Crabtree J, Zhao Q, Lorenzi H, Orvis J, Puiu D, Melake-Berhan A, Jones KM, Redman J, Chen G. Draft genome sequence of the oilseed species Ricinus communis. Nat Biotechnol. 2010;28:951-6. 
23. Allan G, Williams A, Rabinowicz PD, Chan AP, Ravel J, Keim P. Worldwide genotyping of castor bean germplasm (Ricinus communis L.) using AFLPS and SSRs. Genet Res Crop Evol. 2007;55:365-78.

24. Wang Z, Hobson N, Galindo L, Zhu S, Shi D, McDill J, Yang L, Hawkins S, Neutelings G, Datla R et al. The genome of flax (Linum usitatissimum) assembled de novo from short shotgun sequence reads. Plant J. 2012;72:461-73.

25. Luo R, Liu B, Xie Y, Li Z, Huang W, Yuan J, He G, Chen Y, Pan Q, Liu Y et al. SOAPdenovo2: an empirically improved memory-efficient short-read de novo assembler. Gigascience. 2012;1(1):18.

26. Rice $\mathrm{P}$, Longden I, Bleasby A. EMBOSS: The European molecular biology open software suite. Trends Genet. 2000;16:276-7.

27. Crouzet J, Trombik T, Fraysse AS, Boutry M. Organization and function of the plant pleiotropic drug resistance $A B C$ transporter family. FEBS Lett. 2006;580:1123-30.

28. Finn RD, Clements J, Eddy SR. HMMER web server: interactive sequence similarity searching. Nucleic Acids Res. 2011;39(Web Server issue):W29-37.

29. Punta M, Coggill PC, Eberhardt RY, Mistry J, Tate J, Boursnell C, Pang N, Forslund K, Ceric G, Clements J. The Pfam protein families database. Nucleic Acids Res. 2012:40(Database issue):D290-301.

30. Phytozome [http://phytozome.jgi.doe.gov/pz/portal.html]. Accessed 28 May 2016.

31. Goodstein DM, Shu S, Howson R, Neupane R, Hayes RD, Fazo J, Mitros T, Dirks W, Hellsten U, Putnam N, Rokhsar DS. Phytozome: a comparative platform for green plant genomics. Nucleic Acids Res. 2012;40(D1):D1178-86.

32. Altschul SF, Gish W, Miller W, Myers EW, Lipman DJ. Basic local alignment search tool. J Mol Biol. 1990;215:403-10.

33. JMP®, Version 11. SAS Institute Inc., Cary, NC, 1989-2007.

34. Merchant SS, Prochnik SE, Vallon O, Harris EH, Karpowicz SJ, Witman GB, Terry A, Salamov A, Fritz-Laylin LK, Marechal-Drouard L. The Chlamydomonas genome reveals the evolution of key animal and plant functions. Science. 2007:318:245-50.

35. Geisler M, Murphy AS. The ABC of auxin transport: the role of $\mathrm{p}$ glycoproteins in plant development. FEBS Lett. 2006;580:1094-102.

36. Kim DY, Bovet L, Kushnir S, Noh EW, Martinoia E, Lee Y. AtATM3 is involved in heavy metal resistance in Arabidopsis. Plant Physiol. 2006;140:922-32.

37. Chen S, Sanchez-Fernandez R, Lyver ER, Dancis A, Rea PA. Functional characterization of AtATM1, AtATM2, and AtATM3, a subfamily of Arabidopsis half-molecule ATP-binding cassette transporters implicated in iron homeostasis. J Biol Chem. 2007;282:21561-71.

38. Larsen PB, Cancel J, Rounds M, Ochoa V. Arabidopsis ALS1 encodes a root tip and stele localized half type $A B C$ transporter required for root growth in an aluminum toxic environment. Planta. 2007;225:1447-58.

39. Klein M, Burla B, Martinoia E. The multidrug resistance-associated protein (MRP/ABCC) subfamily of ATP-binding cassette transporters in plants. FEBS Lett. 2006;580:1112-22

40. Pighin JA, Zheng H, Balakshin LJ, Goodman IP, Western TL, Jetter R, Kunst L, Samuels AL. Plant cuticular lipid export requires an ABC transporter. Science. 2004;306:702-4.

41. Panikashvili D, Savaldi-Goldstein S, Mandel T, Yifhar T, Franke RB, Hofer R, Schreiber L, Chory J, Aharoni A. The Arabidopsis DESPERADO/AtWBC11 transporter is required for cutin and wax secretion. Plant Physiol. 2007;145:1345-60.

42. Lang I, Hodak L, Friedl T, Feussner I. Fatty acid profiles and their distribution patterns in microalgae: a comprehensive analysis of more than 2000 strains from the SAG culture collection. BMC Biol. 2011;11:124.

43. Khoshnevis S, Gross T, Rotte C, Baierlein C, Ficner R, Krebber H. The ironsulphur protein RNase $\mathrm{L}$ inhibitor functions in translation termination. EMBO Rep. 2010;11:214-9.

44. Sarmiento C, Nigul L, Kazantseva J, Buschmann M, Truve E. AtRLI2 is an endogenous suppressor of RNA silencing. Plant Mol Biol. 2006;61:153-63.

45. Barthelme $D$, Dinkelaker $S$, Albers S-V, Londei $P$, Ermler $U$, Tampé $R$. Ribosome recycling depends on a mechanistic link between the FeS cluster domain and a conformational switch of the twin-ATPase ABCE1. Proc Natl Acad Sci U S A. 2011;108:3228-33.

46. Kimball SR. Eukaryotic initiation factor elF2. Intl J Biochem Cell Biol. 1999;31:25-9

47. Tyzack JK, Wang X, Belsham GJ, Proud CG. ABC50 interacts with eukaryotic initiation factor 2 and associates with the ribosome in an ATP-dependent manner. J Biol Chem. 2000;275:34131-9.

48. Paytubi S, Wang X, Lam YW, Izquierdo L, Hunter MJ, Jan E, Hundal HS, Proud CG. ABC50 promotes translation initiation in mammalian cells. J Biol Chem. 2009;284:24061-73.

49. Berger SA. Increasing protein production by increasing ABC50 expression or activity. 2012. US Patent Publication US 20120094329 A1.
50. Kaminski WE, Piehler A, Wenzel JJ. ABC A-subfamily transporters: structure, function and disease. Biochim Biophys Acta. 2006;1762:510-24.

51. Garcia O, Bouige P, Forestier C, Dassa E. Inventory and comparative analysis of rice and Arabidopsis ATP-binding cassette (ABC) systems. J Mol Biol. 2004;343:249-65.

52. Saier MH. A functional-phylogenetic classification system for transmembrane solute transporters. Microbiol Mol Biol Rev. 2000;64:354.

\section{Submit your next manuscript to BioMed Central and we will help you at every step:}

- We accept pre-submission inquiries

- Our selector tool helps you to find the most relevant journal

- We provide round the clock customer support

- Convenient online submission

- Thorough peer review

- Inclusion in PubMed and all major indexing services

- Maximum visibility for your research

Submit your manuscript at www.biomedcentral.com/submit
C Biomed Central 